\title{
Assessment of factors for the development of sustainable entrepreneurship in Russia
}

\author{
Timur Absalyamov*1, Svetlana Absalyamova1, Rustem Sakhapov ${ }^{2[0000-0001-9665-1251], ~ a n d ~}$ \\ Mukhammat Gatiyatullin ${ }^{2}$ \\ ${ }^{1}$ Kazan Federal University, 420012 Kazan, Russia \\ ${ }^{2}$ Kazan State University of Architecture and Engineering, 420043 Kazan, Russia
}

\begin{abstract}
The article discusses the factors contributing to the development of sustainable entrepreneurship in Russia. In addition to the main economic factors, such as GRP, per capita income, investment in fixed assets, development of transport infrastructure, etc., frequently studied by researchers, we identified and examined factors the influence of which requires additional studies. We included the volume of tourist flow, the region's participation in mega-events, the presence of special economic zones, the gender composition of the population, the share of urban population in the region, the number of students, etc. Particular attention is paid to the impact of the sharing economy on the development of entrepreneurship.

Keywords. Entrepreneurship, sustainable development, sharing economy, regions of Russia, non-economic factors, factor analysis.
\end{abstract}

\section{Introduction}

Nowadays Russian economic science and practice steadily revise the basic approaches to choosing the ways and instruments of modernization and institutional reform of the economy [1-4]. The role and importance of entrepreneurship in this process is increasing, which is designed to block crisis phenomena and accelerate the transition of the domestic economy to a progressive development vector [5-8].

The intensification of research and development in this field took place in the 1950s, after the adoption of special state programs to support entrepreneurship. The authors of the documents were mainly scientists from leading universities $[9,10]$.

Since the end of the $1980^{\text {s }}$, entrepreneurship has become an object of constant research by Russian scientists and practitioners [11-14]. However, despite the availability of a large array of scientific and practical information devoted to the study of the problems of entrepreneurship development, the search for a model for the sustainable development of small and medium-sized businesses and the identification of regional features do not lose their relevance [15-17].

The study of the influence of such factors as gender composition of the population, age composition, unemployment rate, etc. is of increasing interest. Moreover, new forms of

${ }^{*}$ Corresponding author: abstimur44@gmail.com 
entrepreneurship that appear in the context of sustainable economy and sharing economy require a lot of attention as well [18-20].

\section{Materials and methods}

To write this paper, we used statistical data from the Federal State Statistics Service of the Russian Federation, analytical reports, periodicals and the Internet [21-24]. The statistical analysis was conducted using R-Studio software package.

Moreover, we used the methods of logical comparison, analysis and synthesis, methods of statistical groupings and classifications, expert estimates, and scientific observations.

The practical significance of the research results is determined by the main provisions, generalizations, conclusions and recommendations, which are designed to enhance the process of realizing the entrepreneurial potential of the Russian Federation subjects.

\section{Results and discussion}

First, let us consider the factors of development of small and medium-sized enterprises (SME) related to the tourism industry. By this we mean the number of tourists who visited the subject of the Russian Federation during the year and the number of mega cultural and sports events.

Fig. 1 shows a direct linear relationship between the volume of tourist flow and the number of small enterprises in the region. This means that tourism development really plays a big role for small businesses.

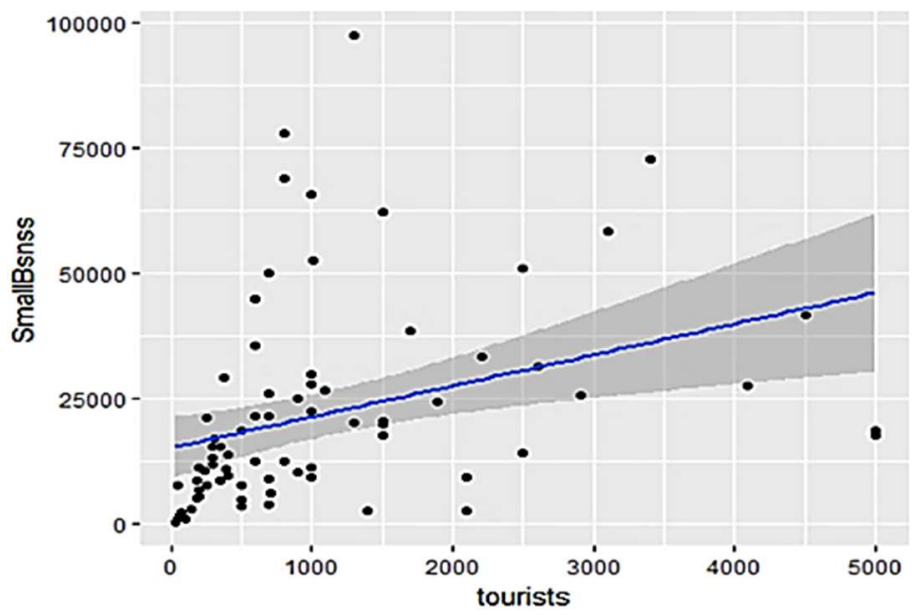

Fig. 1. The relationship between the number of small businesses and the tourist flow during the year in the subjects of the Russian Federation.

The box plot (Fig. 2) shows that there is a big difference in the number of small enterprises between regions that have held sporting or cultural mega-events over the past 10 years, and which have not held such events. Here we can say that mega-events bring modern infrastructure to the regions, which, of course, have a positive effect on both the economy and entrepreneurship. The recognition of the region is also increasing, the number of tourists, both domestic and international, is growing. It is worth noting that the regions conducting mega-events, as a rule, were successful even before they were held, and this factor only increased the pace of development. 


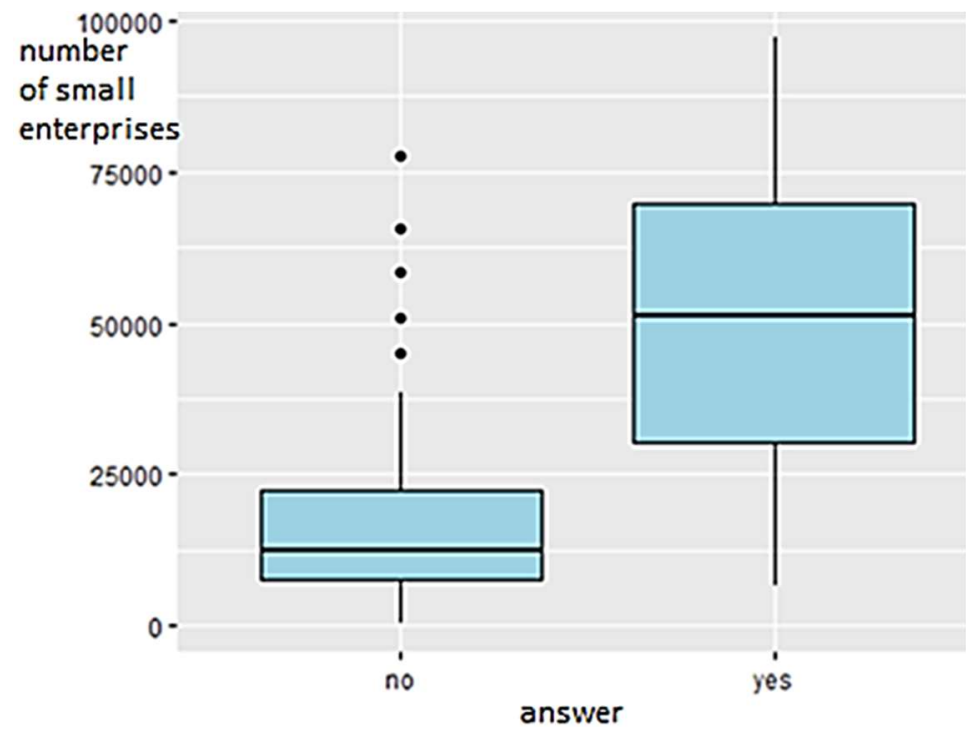

Fig. 2. Distribution of the number of small enterprises in the regions that have held and have not held mega-events over the past 10 years.

Now let us consider the nature of the impact of special economic zones (SEZ) in the constituent entity of the Russian Federation.

Fig. 3 shows that regions with special economic zones have a larger number of small enterprises. At the same time, this factor cannot be crucial - we see that the median number of small enterprises in regions with SEZs is only slightly higher than the same indicator in regions without SEZs.

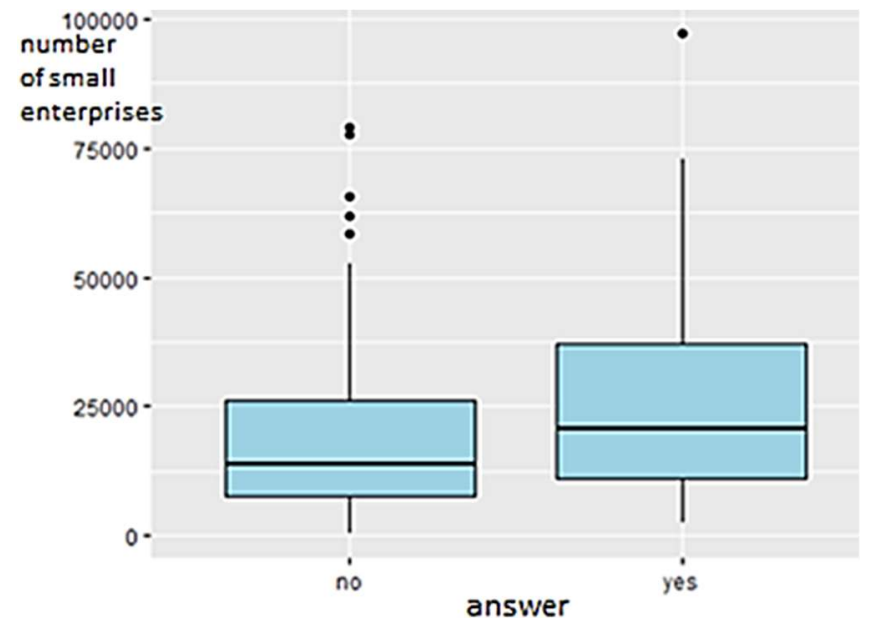

Fig. 3. The distribution the number of small enterprises in constituent entities with and without Special Economic Zones.

It is interesting to consider the gender factor. Fig. 4 shows the relationship between the number of small enterprises and the proportion of the male population in the region. We observe that with an increase in the share of the male population, there is a decline in the number of small enterprises. This is also due to the fact that these are regions of the Far North, 
where the proportion of the male population is higher. At the same time, these same regions are developing in a quite isolated way and entrepreneurship opportunities there are limited.

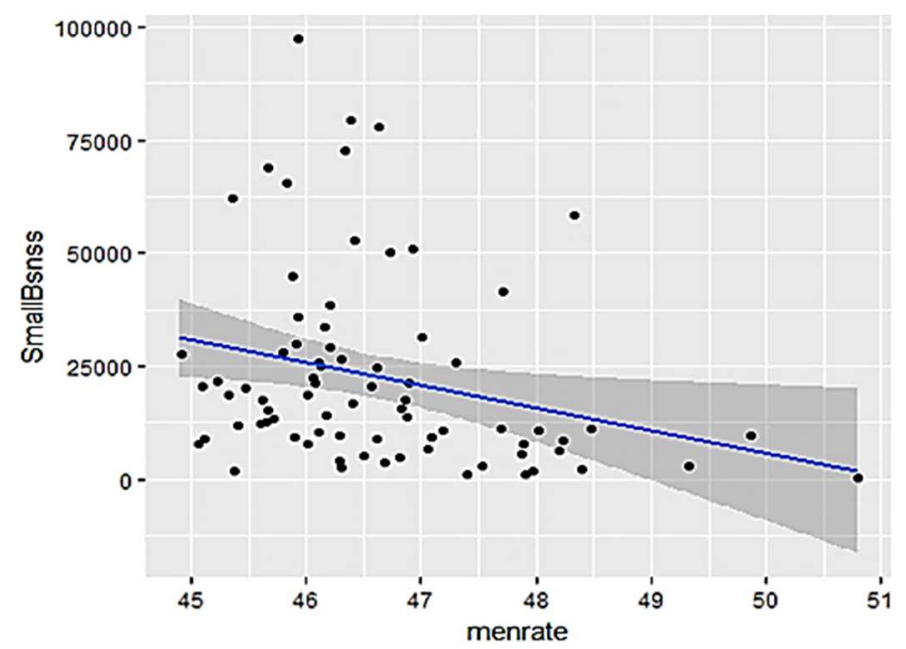

Fig. 4. The relationship between the number of small enterprises and the share of male population in the subjects of the Russian Federation.

Let us try to look at the ratio of the urban population share in the region and the number of small enterprises. Here we see a direct relationship. With an increase in the share of the urban population, the number of small enterprises also tends to increase.

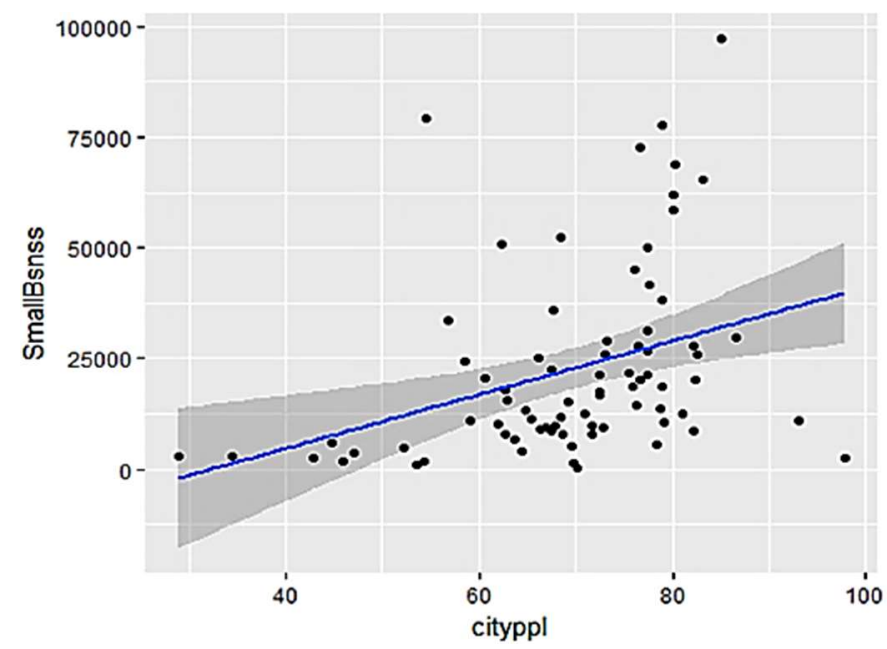

Fig. 5. The relationship between the number of small enterprises and the share of urban population in the constituent entities of the Russian Federation.

A direct correlation is observed between the number of students per 10000 people living in the region and the number of small enterprises. This once again confirms the fact that universities are closely interconnected with the development of entrepreneurship. 


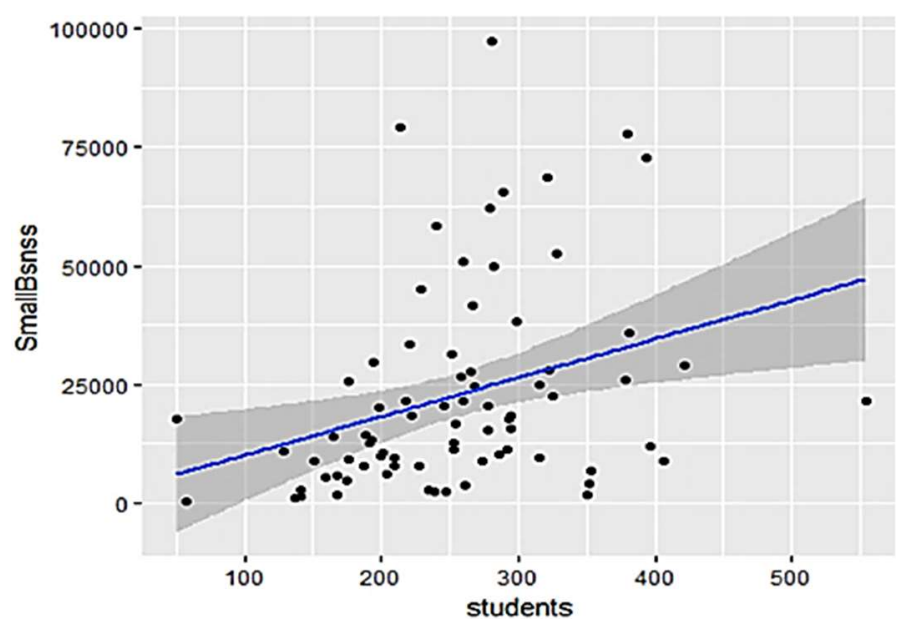

Fig. 6. The ratio between the number of small enterprises and the number of students per 10000 people living in the regions of the Russian Federation.

An interesting picture is observed when assessing the relationship between the distance of the capital of a constituent entity of the Russian Federation to Moscow and the number of small enterprises.

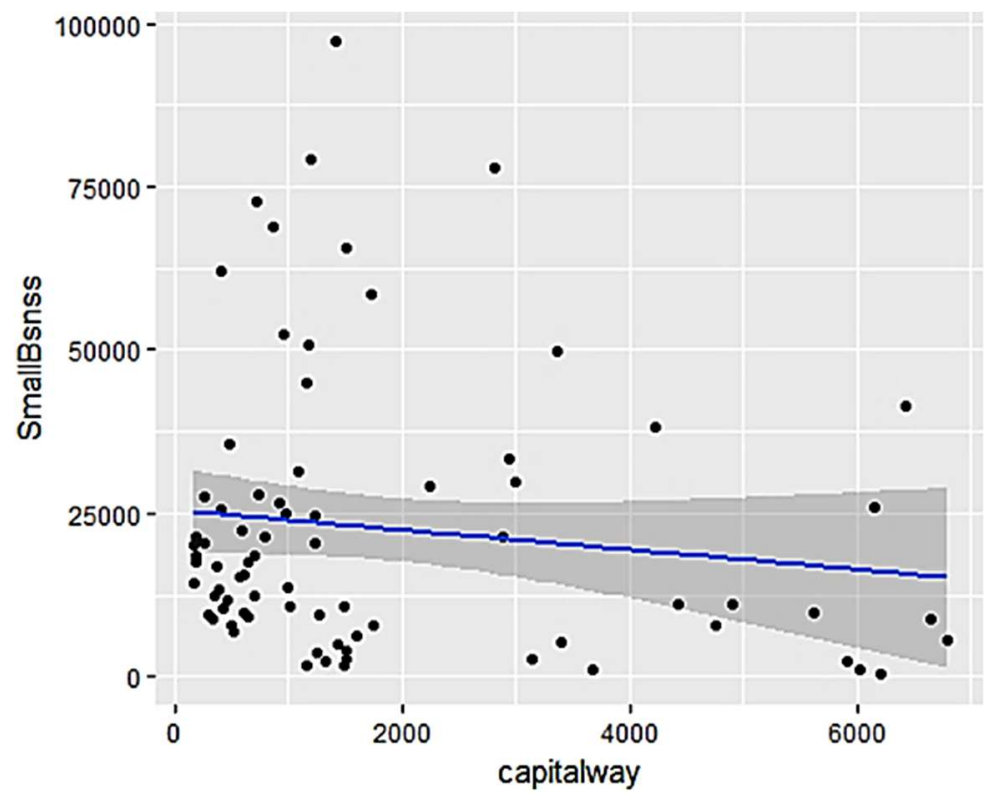

Fig. 7. The relationship between the number of small enterprises and the distance between Moscow and the capital of the constituent entity of the Russian Federation.

With increasing distance, the number of small enterprises decreases, which is to be expected. However, the figure shows that the most successful regions are mainly located at a distance of 700 to $2000 \mathrm{~km}$ from the capital.

According to existing research, the unemployment rate in the region has a significant impact on the activity of small businesses. The hypothesis is put forward that the higher the unemployment rate, the smaller entrepreneurs there are. 


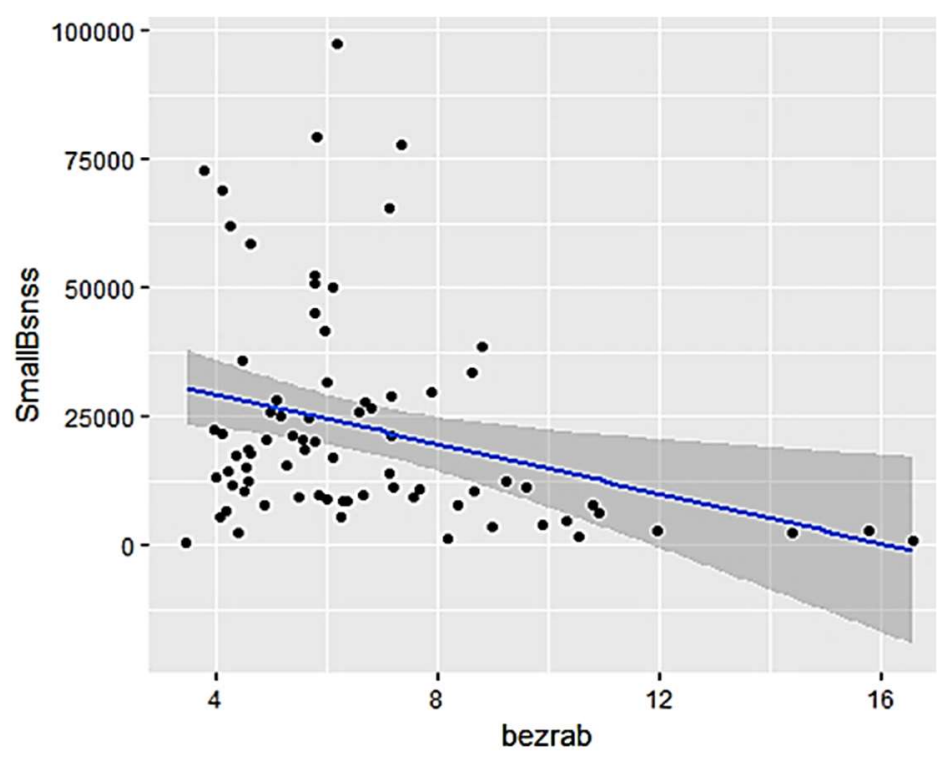

Fig. 8. Dependence between unemployment and entrepreneurial activity in the regions of the Russian Federation.

Fig. 8 shows that there is a group of regions where unemployment really has a positive impact on the development of entrepreneurial activity. This dependence is most noticeable in economically developed regions, where even a slight increase in unemployment improves the entrepreneurial activity, serves as a kind of shock absorber of social tension.

However, in depressed regions with high unemployment, an increase in the number of unemployed causes a growth in the gray labor market rather than entrepreneurial activity, as the local population does not have financial opportunities to set up their own business.

In recent times, entrepreneurship has been strongly influenced by phenomenon of sharing economy $[25,26]$. The sharing economy posed a serious challenge to traditional economic models: Yandex. Taxi and Uber for taxi companies, Airbnb for hotel chains, You Do for repair companies [27, 28]. In the future, it will be possible to see many other hybrid options for joint business.

Even today, a wide range of cultural and social processes are related to sharing, which influences a lot of modern trends [29]. Sharing economy can facilitate the development of sustainable entrepreneurship as it calls for a more rational use of resources [30].

The main contribution to the volume and growth of sharing economy in Russia is made by $\mathrm{C} 2 \mathrm{C}$ sales $(72 \%$ of the transaction volume in 2018$)$, freelance services (19\%), transport (car sharing and carpooling - 5\%) and short-term P2P rental of premises (2\%) [31]. Research tells us that the advanced development of sharing is observed in Russian cities with a population of over one million people. This is due to the fact that it is easier to gain a critical mass of supply and demand there, which is an important condition for making joint consumption convenient and reliable.

\section{Conclusion}

In this paper we tested the influence of various factors on the entrepreneurial activity of the region and obtained controversial results that need further research in terms of refuting or confirming their influence on entrepreneurial activity.

We should note that a group of factors is aimed at stimulating the involvement of the population in the development of entrepreneurial activity. Among them, we can distinguish 
state measures to support entrepreneurship and improve the business climate; the creation of special economic zones; mega-cultural and sporting events in the region and others. Another group can be conditionally called demand factors for the results of entrepreneurial activity, since they are determined by the demographic, gender composition of the population, their income, unemployment in the region and other components.

The conducted study allows us to conclude that in order to activate the entrepreneurial potential, it is necessary to use both groups of factors, since it is impossible to implement state programs without increasing the purchasing power of the population, changing its demographic composition (population growth, decreasing average age, changing gender composition, etc.) entrepreneurship support.

\section{References}

1. A.I. Ageev, M.V. Gratchev, R.D. Hisrich. Entrepreneurship in the Soviet Union and postsocialist Russia, Small Business Economics 7 (5), 365-376 (1995).

2. A. Chernopyatov, L. Makushenko, V. Popova, N. Antonova. Entrepreneurship development and business activity in the Russian Federation, Journal of Entrepreneurship Education 21 (4), 1-12 (2018).

3. A.M. Chernopyatov. The main directions and mechanisms to improve the institutional environment of Russian entrepreneurship, (2015).

4. W.H. Stewart Jr., J.C. Carland, J.W. Carland, W.E. Watson, R. Sweo. Entrepreneurial dispositions and goal orientations: A comparative exploration of United States and Russian entrepreneurs, Journal of small business management 41 (1), 27-46 (2003).

5. C. Devece, M. Peris-Ortiz, C. Rueda-Armengot. Entrepreneurship during economic crisis: Success factors and paths to failure, Journal of Business Research 69 (11), 53665370 (2016).

6. D. Acemoglu, F.A. Gallego, J.A. Robinson. Institutions, human capital, and development, Annu. Rev. Econ. 6 1, 875-912 (2014).

7. Z.J. Acs, S. Desai, J. Hessels. Entrepreneurship, economic development and institutions, Small business economics 31 3, 219-234 (2008).

8. R. Botsman, R. Rogers. What's mine is yours: how collaborative consumption is changing the way we live, London: UK, Collins (2011).

9. Gustav F. Papanek. The development of entrepreneurship, The American Economic Review 52.2, 46-58 (1962).

10. Harvey Leibenstein. Entrepreneurship and development, The American Economic Review 58.2, 72-83 (1968).

11. N. Kusnezova. Roots and philosophy of Russian entrepreneurship, Journal for East European Management Studies, 45-72 (1999).

12. R.D. Hisrich, M.V. Grachev. The Russian entrepreneur, Journal of Business Venturing, 8 (6), 487-497 (1993).

13. S. Michailova, D.J. McCarthy, S.M. Puffer, G. Shirokova, G. Vega, L. Sokolova. Performance of Russian SMEs: Exploration, exploitation and strategic entrepreneurship, Critical perspectives on international business, (2013).

14. D.L. Sexton, N.B. Bowman-Upton. Entrepreneurship: Creativity and growth. New York: Macmillan, (1991).

15. T. Absalyamov. Tatarstan model of public-private partnership in the field of cultural heritage preservation, Procedia-Social and Behavioral Sciences 188, 214-217 (2015).

16. V. Gimpel'Son. New Russian Entrepreneurship: Sources of Formation and Strategy of Social Action, Problems of Economic Transition 36.12, 24-41 (1994). 
17. T. Gubaidullina, N. Ivanova, S. Absalyamova, T. Yerina. Analysis of national strategies for sustainable development with regard to fundamental conceptual premise, Journal of Physics: Conference Series 1141 (1), 012018.

18. Kun-Huang Huarng. Entrepreneurship for long-term care in sharing economy, International Entrepreneurship and Management Journal 14.1, 97-104 (2018).

19. Mujtaba Ahsan. Entrepreneurship and ethics in the sharing economy: A critical perspective, Journal of Business Ethics, 1-15 (2018).

20. Harald Heinrichs. Sharing economy: a potential new pathway to sustainability, GAIAEcological Perspectives for Science and Society 22.4, 228-231 (2013).

21. Global Entrepreneurship Monitor, GEM Russia 2018/2019. https://gsom.spbu.ru/images/ cms/menu/otchet_cor1_rgb.pdf.

22. Regions of Russia. Socio-economic indicators. R32. Rosstat. M., 1162 (2018).

23. G.I. Abdrahmanova, P.D. Bahtin, L.M. Gohberg et al. Innovation development rating of Russian Federation subjects 5. M.: Higher School of Economics, (2017).

24. Rosstat. Healthcare, 2018. GKS. RU.

25. R. Dyal-chand. Regulating Sharing: The Sharing Economy as an Alternative Capitalist System, Tulane Law Review 90 2, (2015).

26. A. Dassier. Uber: la France va-t-elle rater le virage de l'économie du partage? (2014).

27. L'Express: http://lexpansion.lexpress.fr/actualite/la-france-va-t-elle-rater-le-virage-de-1economie-du-partage_1627132.html.

28. A.I. Romanova, G.M. Zagidullina, A.N. Afanasyeva, R.S. Hkairetdinova. Experience in the region to increase the availability of housing services, Mediterranean Journal of Social Sciences 64 S2, 549-554, (2015).

29. O.V. Bakhareva, A.I. Romanova, R.S. Safina, I.M. Kursina, T.A. Shindina. Infrastructure in the region: long-term investments of institutional investors in Russia, Journal of Advanced Research in Law and Economics 6 3, 488-503 (2015).

30. Ö. Kunday, E.P. Şengüler. A Study on Factors Affecting the Internationalization Process of Small and Medium Enterprises (SMEs), Procedia - Social and Behavioral Sciences, 972-981 (2015).

31. M. Olson, S. Kemp. Sharing Economy, An In-Depth Look at Its Evolution \& Trajectory Across Industries, Minneapolis: Piper Jaffray Investment Research, (2015).

32. RAEC report «Sharing Economy in Russia in 2018», M., (2019). 